\title{
If Only Math Majors Could Write...
}

Bernard L. Madison

University of Arkansas, bmadison@uark.edu

Follow this and additional works at: https://digitalcommons.usf.edu/numeracy

Part of the Mathematics Commons, and the Science and Mathematics Education Commons

\section{Recommended Citation}

Madison, Bernard L.. "If Only Math Majors Could Write...." Numeracy 5, Iss. 1 (2012): Article 6. DOI: http://dx.doi.org/10.5038/1936-4660.5.1.6 


\title{
If Only Math Majors Could Write...
}

\begin{abstract}
This text of the opening plenary address to the 2011 Summit of the Appalachian College Association and the meeting of the National Numeracy Network makes an argument that quantitative reasoning and writing should be taught together. The argument is set up by noting that humanists have historically banished quantitative issues from their study of the liberal arts and that science, engineering, and mathematics education suffers from lack of approaches to learning that promote complex, deeper understanding, most notably integrative and reflective learning. Therefore, everyone would profit from combining writing and quantitative reasoning. Five more specific reasons are discussed, drawing evidence from numerous sources among the twenty-nine references. The reasons given for combining quantitative constructs and language are: (1) To strengthen academic arguments; (2) To strengthen quantitative literacy/reasoning; (3) To interpret and improve public discourse; (4) To encourage quantitative reasoning across the curriculum; and (5) To prepare for the workplace. Underlying the basic argument and the reasons discussed are clear indications that, in present circumstances, teaching quantitative reasoning rests to a large extent on colleges and universities.
\end{abstract}

\section{Keywords}

quantitative reasoning, quantitative literacy, writing

Creative Commons License

(c) (1) (9)

This work is licensed under a Creative Commons Attribution-Noncommercial 4.0 License

\section{Cover Page Footnote}

Bernard L. Madison is professor and former Chair of the Department of Mathematics, University of Arkansas, and former Dean of its Fulbright College of Arts and Sciences. He was founding president of the National Numeracy Network and is a frequent contributor to this journal. 


\section{Introduction}

About a decade ago, Bob Orrill, Lynn Steen and I engaged in extensive email conversations about quantitative literacy (QL) as we worked in Bob's initiative on QL. At some point in that conversation, Bob wrote to me in an email, "Quantitative Literacy is a cultural field where language and quantitative constructs merge and are no longer one or the other." I believed then and still believe that this observation captures the essence of QL and highlights why I also believe that quantitative literacy is a better term than numeracy, the term used in much of the world outside the U.S.

Bob, historian and Rhodes scholar, referred to himself as being "quantitatively oblivious." In his essay in Calculation vs. Context ${ }^{1}$ (Orrill 2007 p.47), Bob begins with an account of an encounter between philosopher George Santayana and Charles Eliot, then - circa 1890 - president of Harvard College to make the point that many in the humanities were discontent with the intrusion of quantitative issues into liberal education. Orrill writes (p. 49), "Without much exaggeration, one could say that they [humanists] entirely banished quantitative issues from their vision of liberal education." Orrill continues, "This, I might add, was essentially the character of my own educational experience. As an undergraduate, my studies were mostly of a humanistic nature; and, looking back, I cannot recall even once being asked to address a serious quantitative question in completing a large array of courses devoted to history, literature, philosophy, and the arts. This surely contributed to my becoming quantitatively oblivious."

On the other hand, scientists and engineers were being educated (and still are) with minimal attention to the humanities. Many mathematicians, including the author, were educated with little attention to the use of mathematics in the real world, a mathematics education that Alan Schoenfeld (2001) referred to as "impoverished." Mixing writing and mathematics was one of the contextual uses of mathematics that was missing. My own school and college education had no art, no philosophy, and very little literature. Writing about mathematics or even writing with numbers was mostly restricted to research papers on mathematics, far from popularized or reflective or integrative materials. The connections between mathematics, science and engineering and the humanities were often limited to

\footnotetext{
${ }^{1}$ Calculation vs. Context is the proceedings of a conference/workshop on Quantitative Literacy and Its Implications for Teacher Education held at Wingspread Conference Center, Racine, WI, June 22-24, 2007. The conference was funded by The Johnson Foundation that operates the Wingspread Center and an NSF grant to the Mathematical Association of America for a project entitled Preparing Mathematicians to Educate Teachers.
} 
lunch. As dean of arts and sciences at the University of Arkansas for ten years, I observed this academic schism almost daily.

Recent research (Nelsen Laird, et al. 2011) points to the effects of this schism on students. Analyses of the National Survey of Student Engagement and Faculty Survey of Student Engagement revealed some differences between science, technology, engineering and mathematics (STEM) and non-STEM undergraduates with regard to approaches to learning that promote more complex, deeper understanding. For this analysis, STEM is science, engineering and mathematics. Non-STEM is arts, humanities and social sciences. In general, STEM faculty use pedagogies that encourage higher-order, integrative and reflective learning significantly less than non-STEM faculty, and STEM seniors experience "deep approaches to learning" less than seniors in non-STEM fields.

My hypothesis today is that we are all losing because we do not take advantage of each other's learning and our disciplines' ways of knowing - and most of all our students are losing. The humanities value writing and critical reading - communication - highly. Frequently, humanities students in our mathematical reasoning class (Dingman and Madison 2010) are talented writers, but profess being terrible at mathematics - and statistics. In reality, they are, in many cases, like Bob Orrill, quantitatively oblivious. Of course, they are quite capable at quantitative reasoning $(\mathrm{QR}),{ }^{2}$ and most of them begin to temper their pessimism before the semester ends.

One of the case studies in the book of case studies that we use centers on an article in Forbes Magazine by Dan Seligman (2002), titled Why Journalists Can't Add. Seligman begins by noting that liberal arts graduates control the media, which doubtless helps the prose - but generates endless screw-ups in numbers. His final line of the article is "If only math majors could write," which is the source for the title for this talk.

The Two Cultures of C. P. Snow ${ }^{3}$ may be an exaggeration of what we have today in quants vs humanists, but we are not far away. Orrill's suggestion (p. 56) for bringing the humanists into the conversation sounds correct to me: "Humanists are more likely to enter the conversation - and remain involved - if they can begin on familiar ground. At the same time, this would also bring QL into contact with the documents and texts about which it so far has had little to say. Here, then might be the makings of a genuine conversation."

One might question whether this schism is a problem - the reasonable don'tfix-the-unbroken query. If the humanists have done quite well without numbers for all these years and science, engineering and mathematics have surely thrived, wherein is the problem? In short, society, and especially U.S. society has become so quantitatively complex that $\mathrm{QR}$ is no longer a luxury or elective; it is liberating

${ }^{2}$ I will use $\mathrm{QR}$ and $\mathrm{QL}$ interchangeably, but I try to view $\mathrm{QR}$ as a process and $\mathrm{QL}$ as a condition.

${ }^{3}$ See http://www.nytimes.com/2009/03/22/books/review/Dizikes-t.html?pagewanted=all 
and essential! Whether you are an engineer or a poet, sound QR is needed for both citizenship and personal prosperity, to say nothing of the workplace. Numbers are everywhere, or as stated in Mathematics and Democracy (Steen 2001), we are "awash in numbers." Blastland and Dilnot (2009), in The Numbers Game, stated this with some clever writing, "For good or ill, [numbers] are today's preeminent public language - and those who speak it rule. Quick and cool, numbers seem to have conquered fact." And Neil Lutsky (2008), in another nice turn of language in Calculation vs. Context, "Numbers are not only important because they are pervasive; they are pervasive because they are important."

I am not speaking about the need for the mathematics of Euclid and Euler more algebra, geometry and calculus. The need is quite different, more critical, and more complex. As Lynn Steen characterized QL, I am speaking about the sophisticated use of elementary mathematics and statistics, often in complex contexts.

Quality writing is not only engaging and elegant but also integrative and reflective, and what STEM students need to learn. QR is essential for life in the U.S., so humanities students need to learn to reason quantitatively. Thus we have an opportunity to make significant educational progress by merging QR with writing - having math majors who can write and English majors who can count.

Why writing with numbers? I give brief discussions of five reasons here.

\section{To strengthen academic arguments}

Quantitative reasoning can strengthen argumentation in writing in many ways adding evidence, framing, focus, and precision. As the Carleton College folks discovered in assessing students' writing portfolios, many opportunities were missed in using QR in argumentation. ${ }^{5}$ You will find that also among your students unless intervention has taken place. As Grawe \& Rutz (2009) noted: "Academic arguments (e.g. analysis of a poem/short story, a historical event, a political outcome, an economic calamity, a journalistic coup, etc.) involve construction of meaning based on evidence; QR supplies an important category of evidence for successful argument."

\footnotetext{
${ }^{4}$ Following up on footnote 1, the conference at Wingspread had 31 participant-scholars from a dozen disciplines and the proceedings, Calculation vs. Context, contains eleven essays on QR/QL. Seven of those essays are referenced in this paper.

${ }^{5}$ Several examples of how to miss such opportunities are given by Miller (2004) in the format of a poor attempt, a better attempt and a best attempt. One illustration of this is: Poor - "In 2002, there were a lot of poor children in the United States (16.7\%)." Better - "In 2002, 16.7\% of the children in the United States were poor." Best - "In 2002, 16.7\% of children were poor, compared to $10.6 \%$ of people aged 18 to 64 , and $10.4 \%$ of those aged 65 or older."
} 


\section{To strengthen quantitative literacy/reasoning}

Using QR in writing requires students to find and evaluate quantitative information. It is not difficult to find information in the age of Google, but evaluation and selection are more challenging. Too much information can lead to fragmented and awkward argument. I recently heard an NPR commentator posit that the amount of information flowing to teenagers has increased more in the past 10 years than in the previous 570 years since Gutenberg introduced book printing.

Milo Schield (2008) - also at Wingspread - pointed to a reason why students do not write using helpful QR. Most do not know how to express simple quantitative ideas in clear English. Many will confuse, for example, the percentage of males who are smokers with the percentage of smokers who are male. Even writers for the New York Times are guilty. Here is an example from the Times (Lewin 2001) of confusing the base (whole-part) of a percentage. The first sentence was the lead sentence on a report of a survey in the print version of the Times, and the second sentence is the corrected lead sentence in the online version of the Times.

After a quarter-century in which women with young children poured into the workplace, the percentage of women in the labor force who had babies younger than 1-year old declined last year.

After a quarter-century in which women with young children poured into the workplace, last year brought the first decline in the percentage of women who have babies younger than 1 year old and are in the work force.

The whole in the first one is women in the labor force while the whole in the second one is women.

\section{To interpret and improve public discourse}

Often graphics need some written explanation, and these written explanations should be consistent with the content of the graphic. Numerous examples appear in public media daily, and most are accurate and well presented. Here are three instances of missing or erroneous written explanations.

- A highway billboard advertises a $110 \%$ off sale of condominiums from $\$ 188,900$. This surely needs some explanation, and explanation might identify the mistake.

- A bar chart graphic notes that the percentage of available positions for caseworkers that were filled increased from 65\% (91 of 101) in August to 80\% (118 of 147) in October. The written explanation stated that the number of caseworkers increased by $15 \%$ from August to October, when, in fact, that number increased by $29.7 \%$ (91 to 118). 
- A pie chart drawn on the interior of a handcuff gave recidivism rates for five types of offenses: violent offenses $(61.7 \%)$, property offenses $(73.8 \%)$, drug offenses $(66.7 \%)$, public-order offenses $(62.2 \%)$, and other offenses $(61.7 \%)$. Obviously all these percentages have different wholes (bases), and the total of the percentages inside this one pie chart is $329.1 \%$. There was no written explanation, and if one were attempted, surely the absurdity of this graphic would be evident.

As indicated above, most graphics in public media do not contain these or other errors, but many graphics can be enhanced and clarified by quality writing to explain mathematical representations.

Some people apparently believe that numbers and statistics need no explanation - that numbers and statistics are indisputable. The catch phrase, "just do the math," is a possible signal of this infallibility. Frequently, numbers and statistics are assumed correct because of weak understanding. Contrary to a noted New Yorker cartoon ${ }^{6}$ by Edward Koren, statistics and numbers do not necessarily speak for themselves. Again, contrary to Frank \& Ernest ${ }^{7}$ cartoon where the number 5 is telling the courtroom bailiff that we can skip the oath because numbers do not lie, numbers are not always trustworthy. Decisions by people create statistics - perhaps not as casually as the May 8, 2008, Dilbert cartoon ${ }^{8}-$ but surely they do. Joel Best (2008) has written a lot about socially constructed statistics - people decide whether to count, what to count, how to count, and how to summarize the counts. This means numbers (or quantities, i.e., numbers with units) are almost never beyond question, and questions involve language.

Students and non-students need to know how to detect mis-uses and appropriate uses of data and statistics. For this purpose, there are two books of helpful essays that I recommend: Stat-Spotting: A Field Guide to Identifying Dubious Data by Joel Best (2010) and The Numbers Game (Blastland and Dilnot 2009) or the British version of the same book, The Tiger that Isn't (Blastland and Dilnot 2008). Reading essays in these will give one a new awareness of how statistics are confused or misrepresented in public media.

We need to change journalists' views that it is OK not to write about numbers or to mangle bases of percentages. The Dan Seligman (2002) article in Forbes Magazine gives several examples of noted journalists' screw-ups (as Seligman characterizes them) on quantitative issues. I have talked to journalists

\footnotetext{
${ }^{6}$ See http://www.condenaststore.com/-se/newyorkerstore.htm?AID=1580762889 and search all magazines for statistics.

${ }^{7}$ http://www.thecomicstrips.com/store/add_strip.php?iid=20769

${ }^{8}$ http://search.dilbert.com/comic/Made\%20Up\%20Numbers Panel 1: I didn't have any accurate numbers so I made one up. Panel 2: Studies have shown that accurate numbers are no more useful that ones you make up. Panel 3: Question - How many studies have shown that? Answer - Eightyseven.
} 
who are quick to say they don't do numbers. Some writers have addressed this issue, and some are very talented at doing so. Here are two examples of highquality writing involving quantities.

Sometimes the absence of a number is as deflating to an article's credibility as the presence of a deceptive one. Few articles noting that President Bush received more votes than any candidate in history also mentioned that more people voted against him than any candidate in history. Quoting Michael Moore's assertion that standing ovations in Greensboro, N.C., proved that "Fahrenheit 9/11" is "a red state movie" disregards the fact that metropolitan Greensboro has over 1.2 million people. You could probably find in a population that large enough people to give a standing $\mathrm{O}$ for a reading of the bylaws of the American Dental Association.

- Dan Okrent (2005), Numbed by the Numbers

THERE'S an overweight man in the White House and his name is George W. Bush.

Yes, the president of the United States, known for his robust good health, is officially overweight, according to the standards of the National Institutes of Health. At 6 feet and 194 pounds, his body mass index, or B.M.I., a measurement of height relative to weight, is 26.4 , and 25 or above is officially overweight for both sexes.

And so President Bush joins about 65 percent of Americans who are overweight or obese - a status derived solely from that body mass index dividing line of 25 .

- Gina Kolata (2004) Tell the truth: Does this index make me look fat?

My only suggestion for these high-quality and informative pieces would be to say that the BMI is a measurement of weight ${ }^{9}$ relative to the square of height.

\section{To encourage $Q R$ across the curriculum}

The contexts for QR/QL are as varied as society itself, and language and circumstances spread across all school and college disciplines and beyond. Some of the most common situations occur in health, sociology, economics, politics, sports, and education. Students need to understand terms such as nominal dollars and acronyms such as GDP, DJIA, S\&P500, BMI, and COLI. We need to broaden and deepen the conversation on campuses about $\mathrm{QR}$, which is far too casual and not nearly as engaging as it needs to be.

\footnotetext{
${ }^{9}$ As one reviewer of this paper noted, in Imperial units the BMI is a measurement of mass multiplied by a coefficient to the square of the height. In SI units the BMI is kilograms per meter squared. Practical uses of the BMI do not make the distinction between weight and mass.
} 
Like writing and critical reading, $\mathrm{QR} / \mathrm{QL}$ is best addressed across the curriculum, but academic leadership for $\mathrm{QR}$ is probably the most daunting obstacle we face. Some, notably Neil Lutsky (2008) and Joel Best (2008), argued at Wingspread that mathematicians should/could not lead QR. Engineer-turnedmathematics educator Hugh Burkhardt (2008) argued that if mathematicians did not do it, it would not happen. One of the first articles (Madison 2001) I wrote on QL was entitled "Quantitative Literacy: Everybody's Orphan."

We desperately need to integrate mathematics and statistics with everyday society - to show their utility and relevance and end inward-looking isolation. Most disciplines - and especially mathematics - are inward looking. Mathematicians are inclined to look for more motivation to learn more mathematics. Quite frankly, most of our disciplines do not see a clear role in general education. And now that general education demands are so enormous, there is quite a deficit of attention. And this is a growing failure of higher education - lack of attention to general education.

\section{To prepare for the workforce}

Surely, this reason is not in doubt. Communicating with words and numbers merging quantitative constructs with language - is a staple of most jobs in this information age. Economist Corri Taylor (2008) in a Wingspread essay on QL for the workplace noted that QL is a type of literacy and "communicating effectively about quantitative topics" emerged from almost every source that Corri cited.

\section{Our QR Course}

At the University of Arkansas, all of our Mathematical Reasoning sections have significant writing components. We use the Casebook (Madison et al. 2009), which contains case studies of twenty-nine media articles, as the principal curricular resource. Recently, Shannon Dingman, Stuart Boersma, Caren Diefenderfer and I (Boersma, et al. 2011) developed a rubric for scoring student QR work. The report of that work is in the current issue of Numeracy, a shining beacon in QR education, thanks to editors Len Vacher and Dorothy Wallace. We began with the AAC\&U VALUE rubric (AAC\&U 2009) that was designed for institutional level assessment of QL or QR. One of the things that our study showed was that writing - rather reading and writing - was a huge part of the rubric. There are six core competencies - interpretation, representation, calculation, analysis/synthesis, assumptions, and communication. We mapped these six to our 234 study questions in our Casebook and found interpretation and communication present in $65 \%$ and $23 \%$ of the questions, respectively. The $23 \%$ is too small and will be larger in the 3rd edition of the Casebook that is being 
prepared this year. One of the things we learned by applying the rubric to our study questions was to word questions more clearly and explicitly to elicit communication.

One of our sections of Mathematical Reasoning has emphasized writing more than the others - in fact, in the spring term it will be taught along with Composition 2: a combined six-hour course with credit for MATH 2813 and ENGL 1023. There are four major paper assignments:

- 1-2 page critical response essay on understanding a large quantity.

- 2-3 page evaluative synthesis on selecting a desired purchase and devising a savings plan to achieve the purchase.

- 2-3 page argumentative synthesis on "state of the union" of a selected situation with a population.

- 5-6 page research paper on a current, negative issue that is important to the student and propose a solution.

We will use three texts: (1) The QR Casebook (Madison, et al. 2009), (2) The St. Martin's Handbook on writing (Lunsford 2011), and (3) The Chicago Guide to Writing about Numbers (Miller 2004).

One of our problems is finding instructors. Many - almost all - of ours do not feel very secure outside their silos of expertise. In my experience, more college faculty are willing/able to teach writing than are willing/able to teach QR. This also indicates why QR is a shared problem between K-12 and higher education, probably falling more heavily on higher education, partly because higher education has more flexibility at the present time. Teaching words and numbers together is more sophisticated than the way we teach writing and mathematics in $\mathrm{K}-12$. The interdisciplinary nature makes this at least a 10-14 issue. At Wingspread, Rich Shavelson (2008), conference keynoter, argued that a proper response to the QL crisis is not a special focus on QL for prospective and practicing K-12 teachers but a broad focus for all students, especially at the introductory college level. So it is our - colleges and universities - problem, and we need to take the lead in finding reasonable responses.

\section{Conclusion}

To close, I hope we can find ways to engage all of us - humanists and others - in "genuine conversations" (as Bob Orrill wrote) on our campuses about QR and put an end to the many apocryphal but close-to-the-truth stories about unabashed admission of being bad at math.

I recently reviewed a pre-publication copy of a book by Jeff Bennett (2011) titled Math for Life: Crucial Ideas You Didn't Learn in School. Jeff opens with a multiple-choice question: Imagine that you're at a party, and you've just struck up 
a conversation with a dynamic, successful businesswoman. Which of the following are you most likely to hear her say during the course of your conversation?
a. "I really don't know how to read very well."
b. "I can't write a grammatically correct sentence."
c. "I'm awful at dealing with people."
d. "I've never been able to think logically."
e. "I'm bad at math."

Jeff writes that we all know the answer is e because we have heard it so many times.

Maybe we can at least add another choice that "I really would like to be better at mixing writing and numbers."

\section{Acknowledgements}

The author is grateful to the Appalachian College Association and the National Numeracy Network for the opportunity to make the presentation leading to this paper. Further, the author acknowledges the helpful suggestions of three reviewers that resulted in improvements.

\section{References}

AAC\&U. See Association of American Colleges and Universities.

Association of American Colleges and Universities. 2009. Assessing learning outcomes:

Lessons from AAC\&U's VALUE project. Peer Review, Winter 2009, 11 (1). http://www.aacu.org/peerreview/pr-wi09/pr-wi09_index.cfm

Bennett, J. 2011. Math for life: Crucial ideas you didn't learn in school. Greenwood, CO: Roberts and Company Publishers.

Best, J. 2008a. Stat-spotting: A field guide to identifying dubious data. Berkeley and Los Angeles, CA: University of California Press.

- 2008b. Beyond calculation: Quantitative literacy and critical thinking about public issues. In Madison and Steen 2008, 125-135.

Blastland, M. and A. Dilnot, 2008. The tiger that isn't: Seeing through a world of numbers. London: Profile Books.

- 2009. The numbers game: The commonsense guide to understanding numbers in the news, in politics, and in life. New York: Gotham Books. (This is the USA version of The tiger that isn't, the previous reference.)

Boersma, S., C. L. Diefenderfer, S. W. Dingman, and B. L. Madison. 2011. Quantitative reasoning in the contemporary world, 3: Assessing student learning. Numeracy 4(2), Article 8. http://dx.doi.org/10.5038/1936-4660.4.2.8

Burkhardt, H. 2008.Quantitative literacy for all: How can we make it happen. In Madison and Steen 2008, 137-162. 
Dingman, S. W. and B. L. Madison. 2010. Quantitative reasoning in the contemporary world, 1: The course and its challenges. Numeracy 3(2), Article 4. http://dx.doi.org/10.5038/1936-4660.3.2.4

Grawe, N. D., and C. A. Rutz. 2009. Integration with writing programs: A strategy for quantitative reasoning program development. Numeracy 2 (2), 1-18. http://dx.doi.org/10.5038/1936-4660.2.2.2

Kolata, G. 2004. Tell the truth: Does this index make me look fat? New York Times, November 28, 2004.

Lewin, T. 2001. More mothers of babies under 1 are staying home. New York Times, October 19, 2001.

Lunsford, A. A. 2011. The St. Martin's handbook, 7th edition. Boston, MA: Bedford/St. Martin's.

Lutsky, N. 2008. Arguing with numbers: Teaching quantitative reasoning through argument and writing. In Madison and Steen 2008, 59-74.

Madison, B. L. 2001. Quantitative literacy: Everybody's orphan. MAA Focus 21(6), $10-11$.

- and L. A. Steen, eds. 2008. Calculation vs. context: Quantitative literacy and its implications for teacher education. Washington, DC: Mathematical Association of America. http://www.maa.org/Ql/calcvscontext.html

Madison, B. L.,S. Boersma, C. L. Diefenderfer, and S. W. Dingman. 2009. Case studies for quantitative reasoning: A casebook of media articles, 2nd edition. New York, NY: Pearson Custom Publishing.

Miller, J. E. 2004. The Chicago guide to writing about numbers. Chicago, IL: University of Chicago Press.

Nelsen Laird, T. F., D. F. Sullivan, C. Zimmerman, and A. C. McCormick. 2011. STEM/Non-STEM differences in engagement at US institutions. Peer Review 13(3), 23-26.

Okrent, D. 2005. Numbed by the numbers, when they just don't add up. New York Times, January 23, 2005

Orrill, R. 2008. Humanism and quantitative literacy. In Madison and Steen 2008, 47-57.

Schield, M. 2008. Quantitative literacy and school mathematics: Percentages and fractions. In Madison and Steen 2008, 87-107.

Schoenfeld, A. 2001. Reflections on an impoverished education. In Steen 2001, 49-54.

Seligman, D. 2002. Why journalists can't add. Forbes Magazine. January 21, 2002.

Shavelson, R. J. 2008. Reflections on quantitative reasoning: An assessment perspective. In Madison and Steen 2008, 27-44.

Steen, L. A., ed. 2001. Mathematics and democracy: The case for quantitative literacy. Princeton, NJ: National Council on Education and the Disciplines. http://www.maa.org/q1/mathanddemocracy.html

. 2004. Achieving quantitative literacy: An urgent challenge for higher education. Washington, DC: Mathematical Association of America.

Taylor, C. 2008. Preparing students for the business of the real (and highly quantitative) world. In Madison and Steen 2008, 109-124. 